\title{
Metformin protects against sevoflurane-induced neuronal apoptosis through the S1P1 and ERK signaling pathways
}

\author{
HUIYU YUE ${ }^{1}$, BIN HU$^{2}$, ZHIKAI LUO ${ }^{2}$ and MEI LIU ${ }^{2}$ \\ ${ }^{1}$ Department of Anesthesiology, Shaan Xi Provincial Tumor Hospital, Xi'an, Shaanxi 710061; \\ ${ }^{2}$ Department of Anesthesiology, Yan'an University Affiliated Hospital, Yan'an, Shaanxi 716000, P.R. China
}

Received May 30, 2018; Accepted October 26, 2018

DOI: $10.3892 /$ etm.2018.7098

\begin{abstract}
The aim of the current study was to investigate whether metformin could counteract sevoflurane-induced neurotoxicity. In vitro experiments on the sevoflurane-induced nerve injury were performed using hippocampal neurons. Neuronal apoptosis was detected by an MTT assay. Protein expression levels of apoptosis-associated genes, including cleaved-caspase-3, apoptosis regulator BAX and apoptosis regulator Bcl-2 were detected by western blot analysis. The mechanism of the effect of metformin on sevoflurane-induced neuronal apoptosis was investigated using a sphingosine 1-phosphate receptor 1 (S1P1) antagonist (VPC23019) and mitogen-activated protein kinase kinase inhibitor (U0126). The current study revealed that metformin may reduce sevoflurane-induced neuronal apoptosis via activating mitogen-activated protein kinase (ERK)1/2 phosphorylation. VPC23019 and U0126 eliminated the neuroprotective effects of metformin on neuronal apoptosis, which suggests that metformin is able to protect against sevoflurane-induced neurotoxicity via activation of the S1P1-dependent ERK1/2 signaling pathway.
\end{abstract}

\section{Introduction}

In recent years, with the rapid development of surgical procedures, the proportion of patients who undergo general anesthesia has increased due to its diverse application, safety and comfort $(1,2)$. With this the increase in the number of surgeries anesthetic complications, such as postoperative cognitive dysfunction, have increased annually (3). The role of anesthetic drugs in the central nervous system has been previously investigated, especially the potential effect on the aptitude and memory of infants and children (4-6).

Correspondence to: Dr Mei Liu, Department of Anesthesiology, Yan'an University Affiliated Hospital, 43 Beida Street, Yan'an, Shaanxi 716000, P.R. China

E-mail: ihki39@163.com

Key words: metformin, sevoflurane, sphingosine 1-phosphate receptor 1 , mitogen-activated protein kinase
Sevoflurane has been widely used due to its rapid induction, early recovery, low impact on liver and kidney function, and stable hemodynamics $(7,8)$. Animal studies demonstrated that sevoflurane can inhibit the proliferation of cortical progenitor cells and promote central nervous system cortical neuron death, thereby reducing the aptitude and memory of newborn animals (9-11). Preclinical experiments have demonstrated that the neurotoxic effect of sevoflurane on the developing brain is associated with neuronal apoptosis and subsequent cognitive dysfunction $(12,13)$. Therefore, a treatment method that can counteract neuronal apoptosis may reduce sevoflurane-induced neurocognitive impairment.

In the central nervous system, sphingomyelin, especially nerve sphingomyelin, is an essential component of oligodendrocytes and the myelin sheath (9). Sphingomyelin can be catalyzed by Phospholipase $\mathrm{C}$ to form ceramide, which is further catalyzed by ceramidase to form sphingosine (12). Subsequently, sphingosine is phosphorylated by sphingosine kinases (SphK) to form sphingosine-1-phosphate (S1P) (14). The S1P signaling pathway can stimulate neuronal growth and survival. Upregulation of S1P in cells has been shown to inhibit the apoptosis of PC12 cells due to the addition of exogenous neuraminic acid or lack of serous fluid $(15,16)$. Additionally, a study revealed that the inactivation of sphingosine kinase 1/S1P signal transmission disrupted the growth and survival of neuronal cells, and damaged the development of neural progenitor cells in the sensory ganglion (17).

Metformin has been demonstrated to be a safe and effective oral hypoglycemic agent that is widely used in the treatment of diabetes $(18,19)$. Studies have demonstrated that metformin promotes the growth of newly-generated neurons in the hippocampus and improves spatial learning and memory in mice $(20,21)$. In the present experimental study, the effect of metformin on sevoflurane-induced neuronal apoptosis and its potential mechanism were assessed.

\section{Materials and methods}

Preparation of hippocampal neurons. A total of 120 male neonatal Sprague-Dawley rats (age, 18 days; weight, 40-45 g) were obtained from Beijing Vital River Laboratory Animal Technology (Beijing, China). Rats were housed in environmentally controlled conditions $\left(21 \pm 2^{\circ} \mathrm{C}\right.$, with a 12 -h light/dark cycle and $30-40 \%$ humidity). All rats had free access to food and 
water. Rats were sacrificed by decapitation and the skin from the heads was removed. The bilateral cerebral hemispheres were separated and placed in a petri dish on ice. The cortex was isolated, and the hippocampus was exposed and removed. Hippocampal tissues were repeatedly washed 3-5 times using pre-cooled $\left(4^{\circ} \mathrm{C}\right)$ Hank's D solution (Gibco; Thermo Fisher Scientific, Inc., Waltham, MA, USA). The hippocampal tissues were crushed and the mixture was centrifuged at $100 \mathrm{x} g$ for $5 \mathrm{~min}$ at $4^{\circ} \mathrm{C}$. The supernatant was discarded and the centrifugation was repeated. The supernatant was discarded and $10 \mu \mathrm{l}$ membrane protease (Tiangen Biotech Co., Ltd., Beijing, China) was added to digest the hippocampal tissue for 15-20 min. The mixture was agitated once every $5 \mathrm{~min}$. Dulbecco's modified Eagle medium (DMEM) containing 10\% fetal bovine serum (FBS; both Gibco; Thermo Fisher Scientific, Inc.) was added to terminate the digestion. The cells were filtered through a 200-mesh copper filter screen. The filtered cells were collected and centrifuged at $100 \mathrm{x}$ g for $5 \mathrm{~min}$ at $4^{\circ} \mathrm{C}$. The supernatant was discarded and the single-cell suspension was prepared by mixing with DMEM. The single-cell suspension was transferred to a culture flask with DMEM and maintained at $37^{\circ} \mathrm{C}$ in a $5 \% \mathrm{CO}_{2}$-humidified incubator, allowing for differential adhesion. Following 1-h incubation, non-adherent neuronal cells were subsequently harvested and the adherent glial cells were isolated. Three independent repeats were performed for each experiment in the current study. The present study was approved by the Animal Ethics Committee of Yan'an University Animal Center (Yan'an, China; approval no. 20170125).

Hippocampal neuron treatment. Hippocampal neurons at logarithmic growth stage were collected and seeded into 96-well plates at a density of $1 \times 10^{4}$ cells/well and cultured for $24 \mathrm{~h}$. Cells were subsequently incubated at $37^{\circ} \mathrm{C}$ with DMEM containing metformin (10 mmol/1; Sigma-Aldrich; Merck KGaA, Darmstadt, Germany), VPC23019 (0.5 $\mu \mathrm{mol} / \mathrm{l}$; Sigma-Aldrich; Merck KGaA) and/or U0126 (5 $\mu \mathrm{mol} / 1$; Sigma-Aldrich; Merck $\mathrm{KGaA}$ ) for $24 \mathrm{~h}$. Five independent repeats were performed for each experiment in the current study.

Exposure of cultured hippocampal neurons to anesthetics. The anesthetic exposure box, a sealed, transparent toughened glass box, was constructed in-house. An appropriate amount of soda lime ( 100 g; Highgreen Medical Technology, Co. Ltd., Weihai, China) was placed at the bottom of the glass box. The lateral aperture on each side of the box was connected by threaded pipe to the anesthesia machine (Dräger Fabius ${ }^{\circledR}$ GS premium (Drägerwerk AG \& Co., KGaA. Lübeck, Germany). The threaded pipe was connected to a gas monitor (FI8000; Shenzhen Yice Medical Test Co., Ltd., Shenzhen, China), so that the sevoflurane concentration could be monitored. The primary hippocampal neurons were seeded into 24-well plates pre-coated with Matrigel basement membrane at a density of $1 \times 10^{6}$ cells/well. Cells were cultured in Neurobasal medium (Gibco; Thermo Fisher Scientific, Inc.) supplemented with $2 \% \mathrm{~B} 27$ and $1 \% \mathrm{~N}_{2}$ and maintained at maintained at $37^{\circ} \mathrm{C}$ in a $5 \% \mathrm{CO}_{2}$-humidified incubator. The primary rat hippocampal neurons were exposed to sevoflurane for 3, 6, 9 and $12 \mathrm{~h}$. The number of viable cells at each time point was analyzed using an MTT assay.
The MTT assay. Cells in the logarithmic grow phase were collected and seeded into the 96-well flat-bottomed plates at a density of $1 \times 10^{4}$ cells per well. Cells were maintained in a $5 \% \mathrm{CO}_{2}$ incubator at $37^{\circ} \mathrm{C}$ until the bottom of the wells were covered with a cell monolayer. Following treatment with metformin (10 mmol/l), VPC23019 (0.5 $\mu \mathrm{mol} / \mathrm{l})$ and/or U0126 (5 $\mu \mathrm{mol} / \mathrm{l})$, the cells were cultured for a further $16-48 \mathrm{~h}$ and $20 \mu \mathrm{l}$ MTT solution $(5 \mathrm{mg} / \mathrm{ml})$ was added to each well and incubated for $4 \mathrm{~h}$. DMSO $(150 \mu \mathrm{l})$ was added to each well and the plates were placed on a rocking bed for $10 \mathrm{~min}$ at a low speed to dissolve the crystals. The absorbance value of each well was measured at a wavelength of $490 \mathrm{~nm}$ using an enzyme-linked immunodetector. The apoptosis rate was calculated using the following: Apoptosis rate=1-cell viability.

Lysis of cultured neurons for extraction of total protein. The culture medium of the hippocampal neurons was removed, PBS was added to each well and the plate was cooled to $4^{\circ} \mathrm{C}$. The plate was gently agitated to perform cell washing. Following the removal of the PBS, the plate was placed on ice for temporary storage. Radioimmunoprecipitation assay buffer (Beyotime Institute of Biotechnology, Haimen, China) was added to each well, and samples were lysed continuously on an ice bed and agitated every 3-5 min for a total of $30 \mathrm{~min}$. The lysed cells were transferred to one side of the culture well with a small scraper, and a pipette was used to transfer the lysate and cell debris to the centrifuge tube. The cell mixture was centrifuged at $1,300 \mathrm{x} \mathrm{g}$ for $5 \mathrm{~min}$ at $4^{\circ} \mathrm{C}$ and the supernatant was stored at $-20^{\circ} \mathrm{C}$ for future use.

Western blot analysis. Following lysis and protein extraction, total protein was quantified using a bicinchoninic acid assay and $50 \mu \mathrm{g}$ protein/lane was separated via SDS-PAGE on a $10 \%$ gel. The separated proteins were subsequently transferred onto polyvinylidene fluoride membranes (EMD Millipore, Billerica, MA, USA) and blocked for $1 \mathrm{~h}$ at room temperature with $5 \%$ non-fat milk powder. The membranes ere incubated with primary antibodies against caspase-3 (1:1,000; cat. no. ab13847), Bax (1:1,000; cat. no. ab3250), Bcl2 (1:1,000; cat. no. ab196495), p-ERK (1:1,000; cat. no. ab201015), ERK $(1: 1,000$; cat. no. ab79853) and b-actin (1:1,000; cat. no ab8226; all Abcam, Cambridge, MA, USA) overnight at $4^{\circ} \mathrm{C}$. The membranes were washed three times for 5 min with Tris-buffered saline with Tween ${ }^{\circledR} 20$ (TBST; Sigma-Aldrich; Merck KGaA). Following the primary incubation, membranes were incubated with fluorescently labeled goat anti-rabbit IgG secondary antibody (1:10,000; ab150077; Abcam, Cambridge, MA, USA) for $1 \mathrm{~h}$ at $37^{\circ} \mathrm{C}$. The membranes were washed with TBST for $10 \mathrm{~min}$ three times, then with PBS for $5 \mathrm{~min}$. Protein bands were visualized using an ECL reagent (cat. no. P0019; Beyotime Institute of Biotechnology) using the Odyssey far-infrared fluorescence scanning imaging system (LI-COR Biosciences, Lincoln, NE, USA). Protein expression was quantified using Image $\mathrm{J}$ software (version 1.38; National Institutes of Health, Bethesda, MD, USA).

Statistical processing. SPSS19.0 statistical software package (IBM Corp., Armonk, NY, USA) was used for data analysis. Comparisons between multiple groups were performed using one-way analysis of variance followed by a post hoc 
test (Fisher's Least Significant Difference). A Chi-squared test was used to analyze the classification data. $\mathrm{P}<0.05$ was considered to indicate a statistically significant difference between groups.

\section{Results}

Sevoflurane increases neuronal apoptosis. Neurons exposed to sevoflurane for 3, 6, 9 and $12 \mathrm{~h}$ were assessed with a MTT assay to evaluate their apoptotic rate. The results demonstrated that sevoflurane-induced neuronal apoptosis was significantly increased in what appeared to be a time-dependent manner when compared with that of the control group (Fig. 1). The apoptotic rate after sevoflurane treatment for $3,6,9$ and $12 \mathrm{~h}$ was $12.4 \pm 0.6,25.5 \pm 2.3,29.8 \pm 2.6$ and $32.2 \pm 3.8 \%$, respectively. No significant changes in the apoptotic rate were identified in the control group after neurons were treated with culture medium without sevoflurane for $9 \mathrm{~h}$.

Metformin reduces the apoptosis rate and pro-apoptosis proteins of sevoflurane-treated cells. In order to verify the protective effect of metformin on sevoflurane-induced neuronal apoptosis, different concentrations of metformin $(2.5,5,10$ and $20 \mathrm{mM})$ were incubated with neurons that were previously exposed to $3 \%$ sevoflurane (Fig. 2). The results revealed that $5 \mathrm{mM}$ metformin could effectively protect neurons from the pro-apoptotic effects of sevoflurane by significantly decreasing the apoptotic rate compared with control cells (Fig. 2A). Metformin appeared to have a dose-dependent protective effect on sevoflurane-induced neuronal apoptosis. Western blotting results also revealed that the protein expression levels of cleaved-caspase-3 and apoptosis regulator BAX (Bax) significantly decreased, and apoptosis regulator Bcl-2 (Bcl2) significantly increased in neurons treated with sevoflurane and $10 \mathrm{mM}$ metformin compared with sevoflurane-treated cells (Fig. 2B-E).

Sphingosine 1-phosphate receptor 1 (S1P1) antagonism increases the apoptosis rate and pro-apoptosis proteins of sevoflurane- and metformin-treated cells in vitro. S1P1 is associated with signal transduction that promotes cell survival functions in neurons (15), thus the authors of the current study speculated that metformin exerted its anti-apoptosis effect on neurons via S1P1. Sevoflurane- and metformin-treated cells incubated with VPC23019, a selective S1P1 antagonist, significantly increased the apoptosis rate compared with sevoflurane- and metformin-treated cells (Fig. 3A). VPC23019 also significantly increased the protein expression levels of cleaved-caspase-3 and Bax, and significantly decreased $\mathrm{Bcl} 2$ compared with sevoflurane- and metformin-treated cells (Fig. 3B-E). These results indicate that metformin could reduce sevoflurane-induced neuronal apoptosis through binding to S1P1.

Metformin prevents neuronal apoptosis by phosphorylation of mitogen-activated protein kinase (ERK)1/2. Studies have suggested that S1P1 activation promotes cell survival functions associated with ERK1/2 $(22,23)$. The current study examined whether metformin could exert anti-apoptotic effects through the activation of ERK1/2. To clarify the role

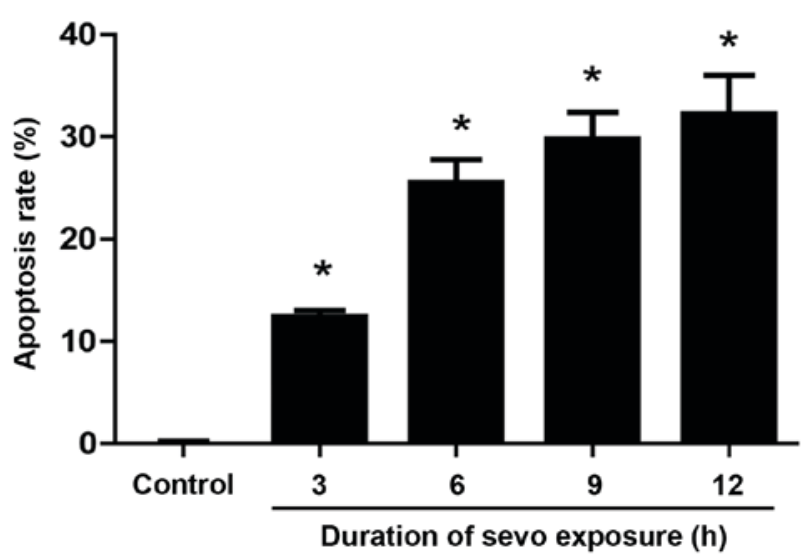

Figure 1. Sevo increases neuronal apoptosis. The apoptotic rate of neurons with sevo exposure after $3,6,9$ and $12 \mathrm{~h}$ assessed by an MTT assay. ${ }^{*} \mathrm{P}<0.05$ vs. Control. Sevo, sevoflurane.

of ERK1/2 in metformin neuroprotection, metformin and U0126, a mitogen-activated protein kinase kinase (MEK) inhibitor, were used to examine sevoflurane-treated neurons. The anti-apoptotic effect of metformin was eliminated by U0126. U0126 significantly increased the apoptosis rate, and cleaved-caspase- 3 and Bax protein expression levels, and significantly decreased $\mathrm{Bcl} 2$ compared with sevoflurane- and metformin-treated cells (Fig. 3).

When the cultured neurons were exposed to sevoflurane, phosphorylated (p-)ERK1/2 protein levels were significantly decreased compared with that of the control group (Fig. 4). However, the level of p-ERK1/2 protein expression in neurons treated with both sevoflurane and metformin was significantly increased compared with cells treated with sevoflurane only. VPC23019 incubation significantly decreased p-ERK1/2 in sevoflurane- and metformin-treated cells compared with those without VPC23019. Since VPC23019-treated neurons could counteract the metformin-induced increase in p-ERK1/2 levels, it could be further demonstrated that metformin activated ERK1/2 signal transduction by binding to S1P1. These data indicate that metformin protected neurons against sevoflurane-induced apoptosis through the activation of the S1P1-dependent ERK1/2 signaling pathway.

\section{Discussion}

Sevoflurane is a commonly used inhaled anesthetic gas $(7,8)$. It remains controversial whether the use of sevoflurane for anesthesia negatively affects the nervous system (10). A number of preclinical studies have revealed that general inhaled anesthetics, such as sevoflurane, can induce the apoptosis of a wide range of cerebral neurons, resulting in specific long-term cognitive and memory impairments $(24,25)$. A number of studies have demonstrated that sevoflurane application not only causes neurotoxicity in normal people, but also leads to neurological damage and neuronal apoptosis in patients with Alzheimer's disease $(26,27)$. Its mechanism of action may be achieved through a variety of signal transduction pathways, including nuclear factor NF-к-B and S1P $(16,28)$.

In the present study, significant hippocampal neuronal apoptosis was induced by $3 \%$ sevoflurane treatment for $3 \mathrm{~h}$ 
A

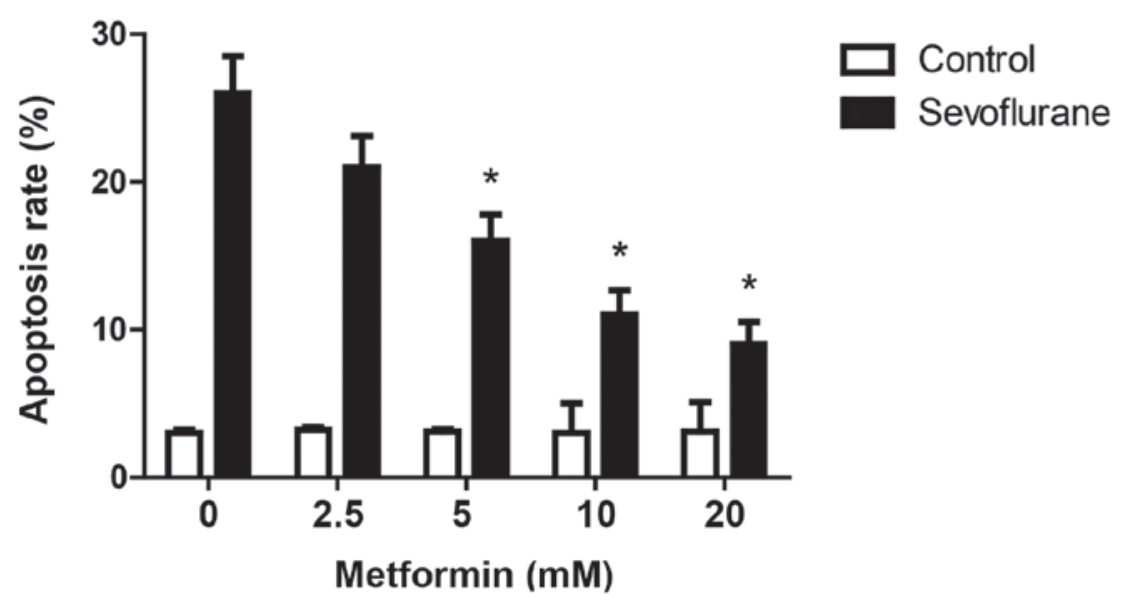

B

C
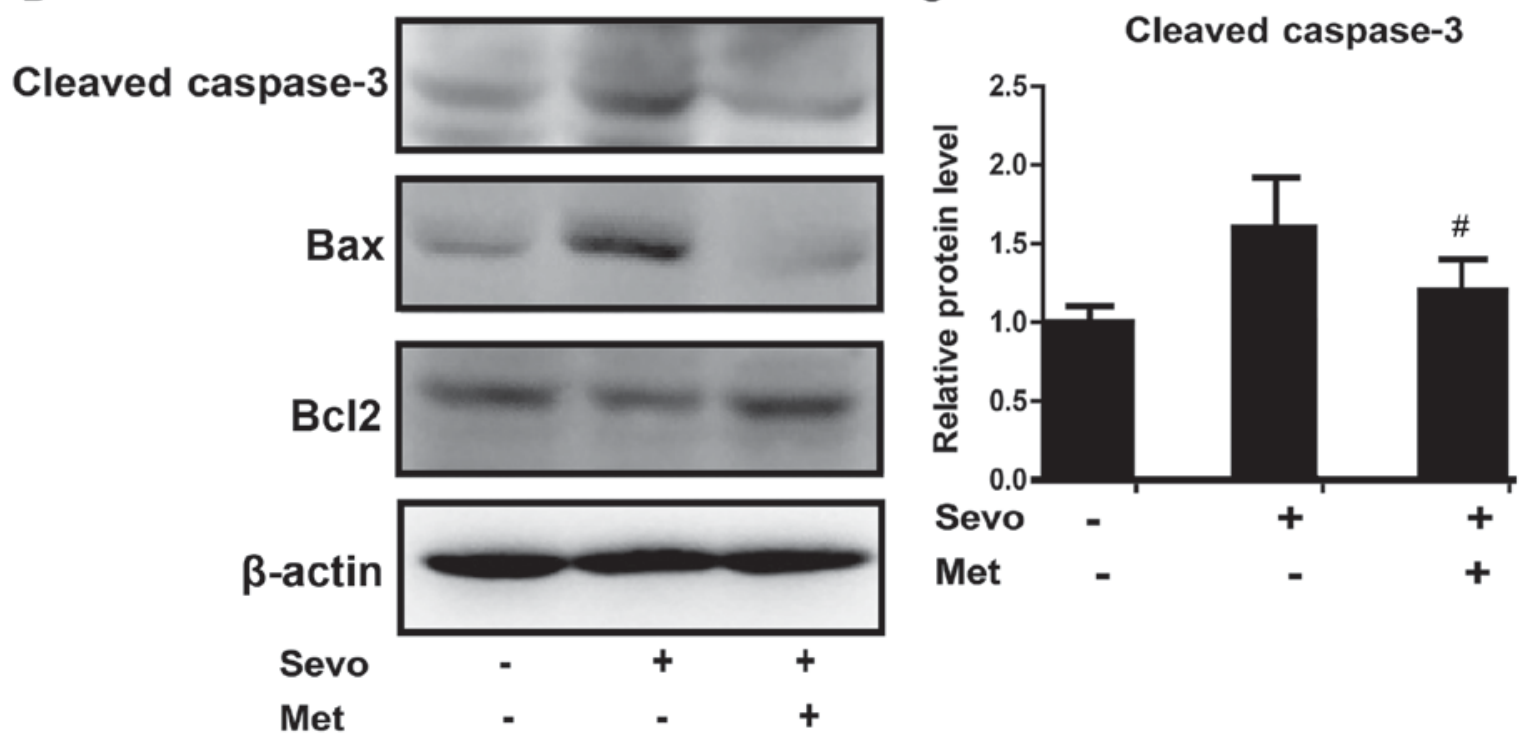

$\mathrm{D}$

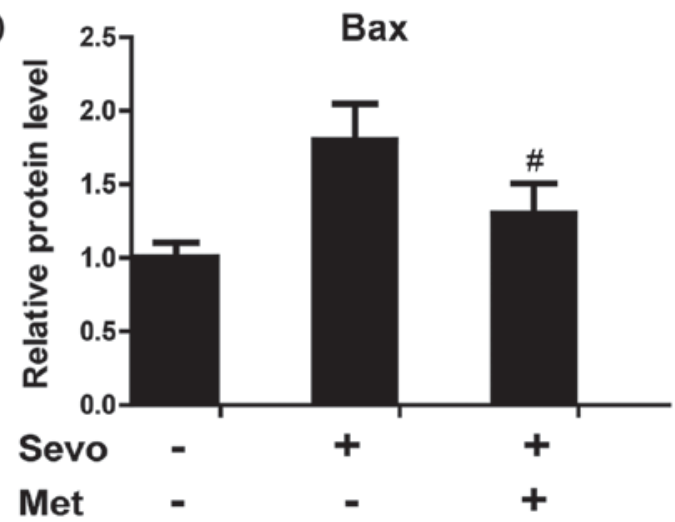

E

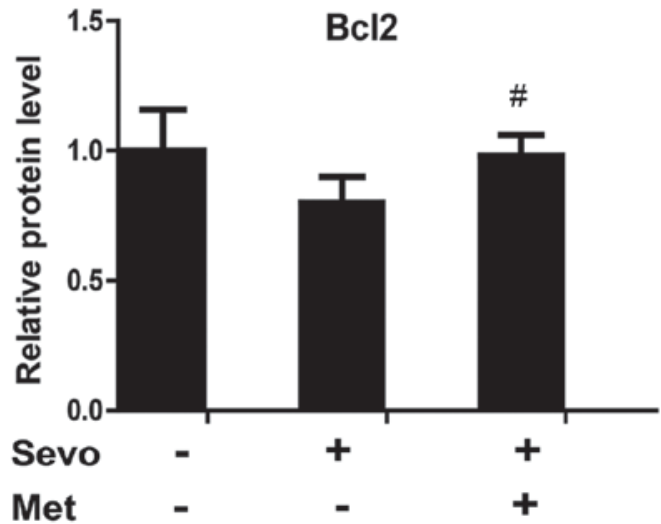

Figure 2. Metformin reduces the apoptosis rate and pro-apoptosis proteins of sevo-treated cells. Neurons were treated with or without metformin or sevo. (A) The apoptotic rate of neurons was assessed by an MTT assay. (B) Protein expression of cleaved-caspase-3, Bax and Bcl2 were assessed using western blotting. Quantification of the protein expression of (C) cleaved-caspase-3, (D) Bax and (E) Bcl2. "P<0.05 vs. Sevo. " P $<0.05$ vs. Sevo. Sevo, sevoflurane; Bax, apoptosis regulator BAX; Bcl2, apoptosis regulator Bcl-2.

and it induced neuronal apoptosis in what appeared to be a time-dependent manner. Metformin was first clinically used as a hypoglycemic agent $(18,19)$. Subsequent studies demonstrated that metformin had different effects on various tissues and systems (29,30). Metformin was revealed to prevent the sevoflurane-induced apoptosis of neurons, which was reversed by a specific S1P1 antagonist (31). However, the mechanism by which metformin produces this protective effect on the 
A

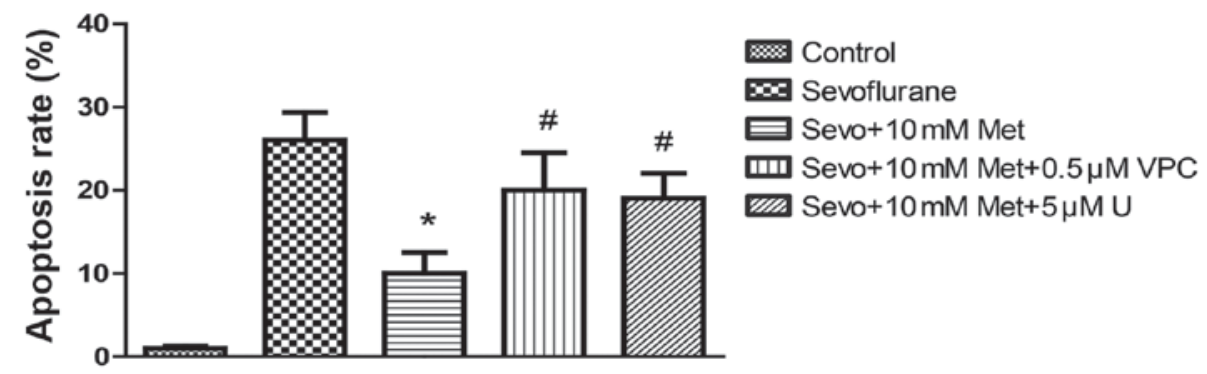

B
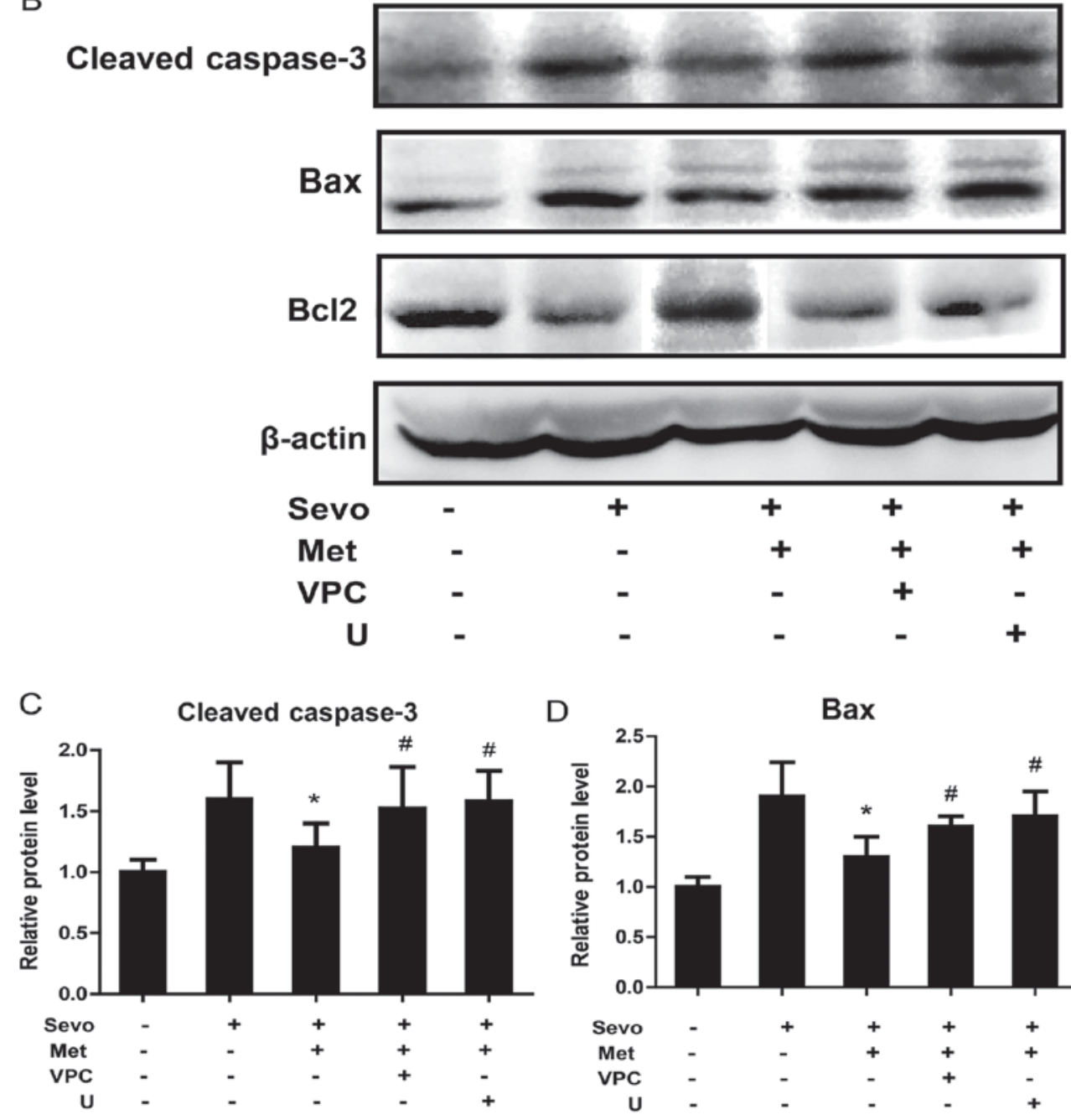

D
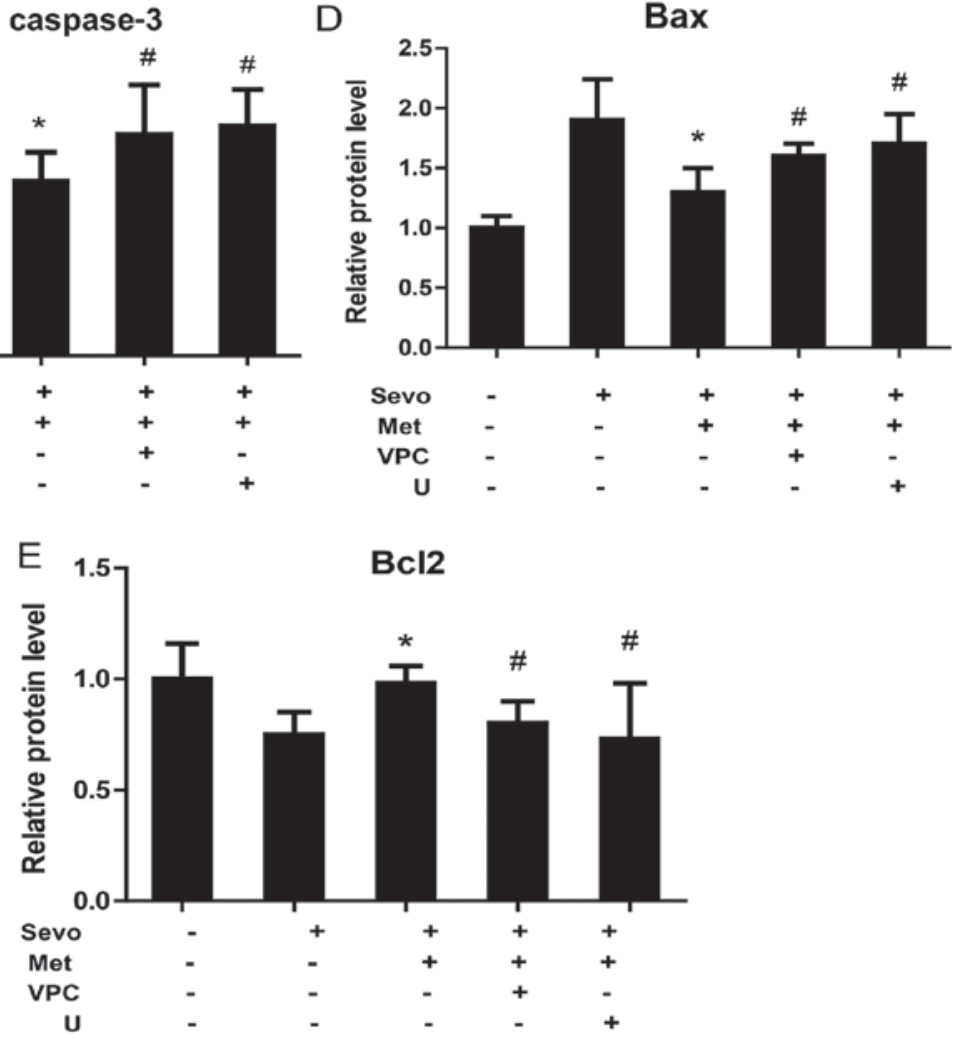

Figure 3. Sphingosine 1-phosphate receptor 1 antagonism increases the apoptosis rate and pro-apoptosis proteins of sevo- and metformin-treated cells in vitro. Neurons were untreated, or treated with sevo, sevo and met, sevo and met and VPC or sevo and met and U. (A) The apoptotic rate of neurons was assessed by an MTT assay. (B) Protein expression of cleaved-caspase-3, Bax and Bcl2 were assessed using western blotting. Quantification of the protein expression of (C) cleaved-caspase-3, (D) Bax and (E) Bcl2. "P<0.05 vs. Sevo. " $\mathrm{P}<0.05$ vs. Sevo+10 mM Met. Sevo, sevoflurane; Met, metformin; VPC, VPC23019 (a sphingosine 1-phosphate receptor 1 antagonist); U, U0126 (a mitogen-activated protein kinase kinase inhibitor); Bax, apoptosis regulator BAX; Bcl2, apoptosis regulator Bcl-2. 

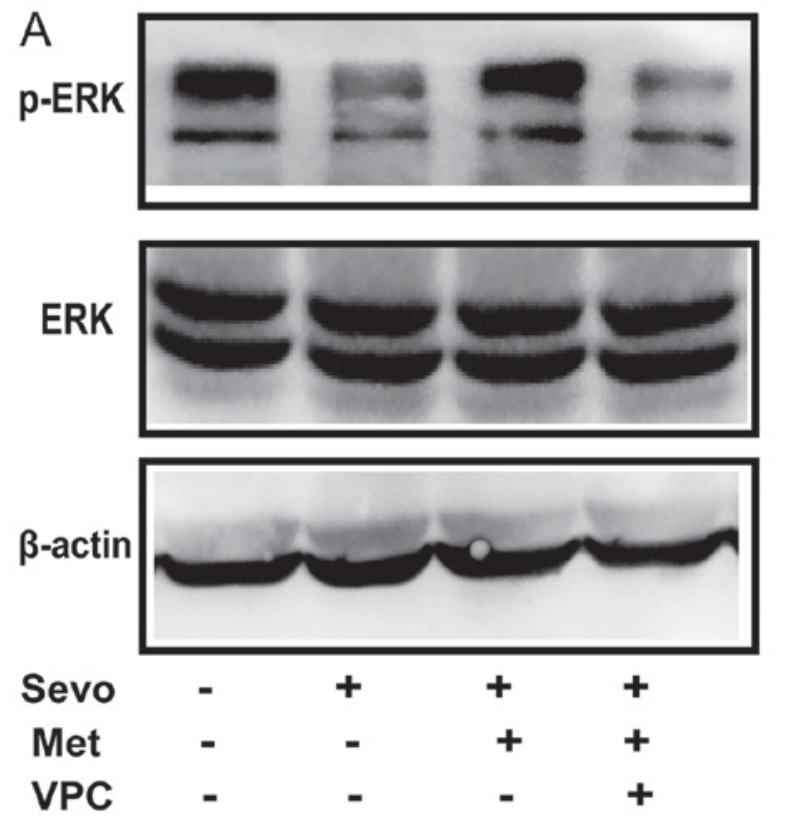

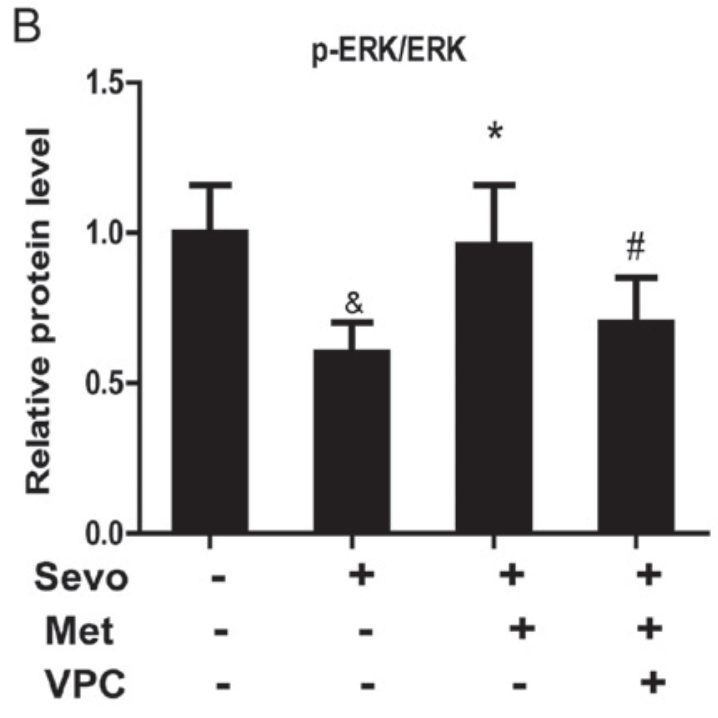

Figure 4. (A) Metformin prevents neuronal apoptosis by phosphorylation of ERK1/2. Neurons were untreated, or treated with sevo, sevo and met or sevo and met and VPC. (B) Protein expression of ERK and p-ERK. Quantification of the ERK and p-ERK protein expression. ${ }^{\&} \mathrm{P}<0.05$ vs. Control; ${ }^{*} \mathrm{P}<0.05$ vs. Sevo; "P<0.05 vs. Sevo + 10 mM Met. Sevo, sevoflurane; Met, metformin; VPC, VPC23019 (a sphingosine 1-phosphate receptor 1 antagonist); ERK, mitogen-activated protein kinase 1/2; p-ERK, phosphorylated ERK.

nervous system remains unclear. Currently, it is hypothesized that metformin can reduce neuronal apoptosis, and protect against lymphocyte aggregation, inflammatory responses and blood vessel dysfunction (32-34).

Previous studies have determined that the S1P signaling pathway can stimulate neuronal growth and survival. It has been reported that S1P can promote the survival of PC12 cells and cultured midbrain neurons $(16,35)$.

Studies have suggested that the downregulation of ERK is correlated with anesthetics-induced neuronal apoptosis $(36,37)$. The current study demonstrated that $\mathrm{p}$-ERK1/2 levels significantly decreased in the sevoflurane-exposed group when compared with that of the control group. However, p-ERK1/2 levels in sevoflurane- and metformin-treated neurons were almost normal. VPC23019 treatment decreased the metformin-induced increase in p-ERK1/2 levels, therefore metformin may activate ERK1/2 signal transduction by binding to S1P1. Additionally, the anti-apoptotic effect of metformin was eliminated by U0126, indicating that metformin protected neurons from sevoflurane-induced apoptosis via activating the S1P1-dependent ERK1/2 signaling pathway.

The present study indicated that the ERK1/2 signal transduction pathway serves an important role in anesthetics-induced neuronal apoptosis. Maintaining the level of p-ERK1/2 during anesthesia helps to maintain the viability of neurons (38). The results of the current study also indicated that metformin regulated sevoflurane-induced neuronal apoptosis through the regulation of Bcl-2 and Bax. Metformin was demonstrated to protect neurons against sevoflurane-induced apoptosis through the activation of the S1P1-dependent ERK1/2 signaling pathway. The present study demonstrated that metformin is able to protect against sevoflurane-induced neurotoxicity possibly through activation of the S1P1-dependent ERK1/2 signaling pathway.

\section{Acknowledgements}

Not applicable.

\section{Funding}

The present study was funded by Shaanxi Self-heating Science Foundation Project Fund (grant no. 2014jm2-8176).

\section{Availability of data and materials}

All datasets used and/or generated during the present study are available from the corresponding author in reasonable request.

\section{Authors' contributions}

HY and ML designed the study, performed the experiments and prepared the manuscript. $\mathrm{HY}$ and $\mathrm{BH}$ collected the data, and HY and ZL analyzed the data. All authors read and approved the final manuscript.

\section{Ethics approval and consent to participate}

The present study was approved by the Animal Ethics Committee of Yan'an University Animal Center (Yan'an, Shaanxi).

\section{Patient consent for publication}

Not applicable.

\section{Competing interests}

The authors declare that they have no competing interests. 


\section{References}

1. Wan Hassan WMN, Tan HS and Mohamed Zaini RH: Comparison of the effects of dexmedetomidine on the induction of anaesthesia using marsh and schnider pharmacokinetic models of propofol Target-Controlled infusion. Malays J Med Sci 25: 24-31, 2018.

2. Afolayan JM, Areo PO, Adegun PT, Ogundipe KO and Filani AB: Comparison of ease of induction of spinal anaesthesia in sitting with legs parallel on the table versus traditional sitting position. Pan Afr Med J 28: 223, 2017.

3. Anderson BJ: Drug error in paediatric anaesthesia: Current status and where to go now. Curr Opin Anaesthesiol 31: 333-341, 2018.

4. Gautam B, Niroula S, Sharma M and Lama SM: Effects of intrathecal dexmedetomidine as an adjuvant to hyperbaric bupivacaine for spinal anaesthesia in adults undergoing elective infra-umbilical surgery. JNMA J Nepal Med Assoc 56: 379-387, 2017.

5. Schwartz C: Enhanced recovery after posterior minimally invasive total hip arthroplasty with continuous intraarticular anaesthesia. Eur J Orthop Surg Traumatol 28: 761-769, 2018.

6. Moran PJ, Fennessy P and Johnson MZ: Establishing a new national standard for the documentation of regional anaesthesia in Ireland. BMJ Open Qual 6: e000210, 2017.

7. Juodzente D, Macas A, Karveliene B, Petkevicius S and Riskeviciene V: Comparison of the cardiovascular and respiratory effects and sevoflurane requirement in dogs premedicated with two doses of medetomidine and butorphanol undergoing surgical sterilization. Pol J Vet Sci 21: 101-110, 2018.

8. Suzuki T, Kurazumi T, Ueda T, Nagata H, Yamada T, Kosugi S, Hashiguchi S, Ito K and Morisaki H: Desflurane anesthesia worsens emergence agitation in adult patients undergoing thyroid surgery compared to sevoflurane anesthesia. JA Clin Rep 3: 36, 2017.

9. Zhang LM, Zhang DX, Zhao XC and Sun W: Erythropoietin rescues primary rat cortical neurons by altering the $\operatorname{nrf} 2$ :Bach1 ratio: Roles of extracellular Signal-Regulated kinase 1/2. Neurochem Res: Jan 12, 2017 (Epub ahead of print).

10. Li R, Zhang LM and Sun WB: Erythropoietin rescues primary rat cortical neurons from pyroptosis and apoptosis via Erk1/2-Nrf2/Bach1 signal pathway. Brain Res Bull 130: 236-244, 2017.

11. Zhang DX, Zhang LM, Zhao XC and Sun W: Neuroprotective effects of erythropoietin against sevoflurane-induced neuronal apoptosis in primary rat cortical neurons involving the EPOR-Erk1/2-Nrf2/Bach1 signal pathway. Biomed Pharmacother 87: 332-341, 2017.

12. Jang YE, Jeong SA, Kim SY, Song IK, Lee JH, Kim JT and Kim HS: The efficacy of intraoperative EEG to predict the occurrence of emergence agitation in the postanesthetic room after sevoflurane anesthesia in children. J Perianesth Nurs 33: 45-52, 2018.

13. Lu G, Xu H, Zhao W, Zhang J, Rao D and Xu S: Upregulation of long noncoding RNA Gadd45a is associated with sevoflurane-induced neurotoxicity in rat neural stem cells. Neuroreport 29: 605-614, 2018.

14. Szepanowski F, Derksen A, Steiner I, Meyer Zu Hörste G, Daldrup T, Hartung HP and Kieseier BC: Fingolimod promotes peripheral nerve regeneration via modulation of lysophospholipid signaling. J Neuroinflammation 13: 143, 2016.

15. Cho MC, Park K, Chai JS, Lee SH, Kim SW and Paick JS Involvement of sphingosine-1-phosphate/RhoA/Rho-kinase signaling pathway in corporal fibrosis following cavernous nerve injury in male rats. J Sex Med 8: 712-721, 2011.

16. Joly $\mathrm{S}$ and Pernet V: Sphingosine 1-phosphate receptor 1 is required for retinal ganglion cell survival after optic nerve trauma. J Neurochem 138: 571-586, 2016.

17. Costello RW, Maloney M, Atiyeh M, Gleich G and Walsh MT: Mechanism of sphingosine 1-phosphate- and lysophosphatidic acid-induced up-regulation of adhesion molecules and eosinophil chemoattractant in nerve cells. Int J Mol Sci 12: 3237-3249, 2011.

18. Yuan X, Wei W, Bao Q, Chen H, Jin P and Jiang W: Metformin inhibits glioma cells stemness and epithelial-mesenchymal transition via regulating YAP activity. Biomed Pharmacother 102: 263-270, 2018.
19. Fu X, Pan Y, Cao Q, Li B, Wang S, Du H, Duan N and Li X: Metformin restores electrophysiology of small conductance calcium-activated potassium channels in the atrium of GK diabetic rats. BMC Cardiovasc Disord 18: 63, 2018.

20. Ge XH, Zhu GJ, Geng DQ, Zhang HZ, He JM, Guo AZ, Ma LL and $\mathrm{Yu}$ DH: Metformin protects the brain against ischemia/reperfusion injury through PI3K/Akt1/JNK3 signaling pathways in rats. Physiol Behav 170: 115-123, 2017.

21. Li J, Deng J, Sheng W and Zuo Z: Metformin attenuates Alzheimer's disease-like neuropathology in obese, leptin-resistant mice. Pharmacol Biochem Behav 101: 564-574, 2012.

22. Rutherford C, Childs S, Ohotski J, McGlynn L, Riddick M, MacFarlane S, Tasker D, Pyne S, Pyne NJ, Edwards J and Palmer TM: Regulation of cell survival by sphingosine-1-phosphate receptor S1P1 via reciprocal ERK-dependent suppression of Bim and PI-3-kinase/protein kinase C-mediated upregulation of Mcl-1. Cell Death Dis 4: e927, 2013.

23. Brizuela L, Rábano M, Gangoiti P, Narbona N, Macarulla JM, Trueba M and Gómez-Muñoz A: Sphingosine-1-phosphate stimulates aldosterone secretion through a mechanism involving the PI3K/PKB and MEK/ERK 1/2 pathways. J Lipid Res 48: 2264-2274, 2007

24. SÖbbeler FJ, Carrera I, Pasloske K, Ranasinghe MG, Kircher P and Kästner SBR: Effects of isoflurane, sevoflurane, propofol and alfaxalone on brain metabolism in dogs assessed by proton magnetic resonance spectroscopy ((1)H MRS). BMC Vet Res 14: 69, 2018.

25. Wen T, Wang L, Sun XJ, Zhao X, Zhang GW and Li-Ling J: Sevoflurane preconditioning promotes activation of resident CSCs by transplanted BMSCs via miR-210 in a rat model for myocardial infarction. Oncotarget 8: 114637-114647, 2017.

26. Epstein RH, Maga JM, Mahla ME, Schwenk ES and Bloom MJ: Prevalence of discordant elevations of state entropy and bispectral index in patients at amnestic sevoflurane concentrations: A historical cohort study. Can J Anaesth 65: 512-521, 2018

27. He H, Liu W, Zhou Y, Liu Y, Weng P, Li Y and Fu H: Sevoflurane post-conditioning attenuates traumatic brain injury-induced neuronal apoptosis by promoting autophagy via the PI3K/AKT signaling pathway. Drug Des Devel Ther 12: 629-638, 2018.

28. Zhang YH, Vasko MR and Nicol GD: Intracellular sphingosine 1-phosphate mediates the increased excitability produced by nerve growth factor in rat sensory neurons. J Physiol 575: 101-113, 2006.

29. Pisani A, Riccio E, Bruzzese D and Sabbatini M: Metformin in autosomal dominant polycystic kidney disease: Experimental hypothesis or clinical fact? BMC Nephrol 19: 282, 2018.

30. Ahmed FW, Bakhashab S, Bastaman IT, Crossland RE, Glanville M and Weaver JU: Anti-angiogenic miR-222, miR-195, and miR-21a plasma levels in T1DM are improved by metformin therapy, thus elucidating its cardioprotective effect: The MERIT study. Int J Mol Sci 19: pii: E3242, 2018.

31. Bayes M, Rabasseda X and Prous JR: Gateways to clinical trials. Methods Find Exp Clin Pharmacol 24: 217-248, 2002.

32. Ma J, Liu J, Yu H, Chen Y, Wang Q and Xiang L: Beneficial effect of metformin on nerve regeneration and functional recovery after sciatic nerve crush injury in diabetic rats. Neurochem Res 41: 1130-1137, 2016.

33. Tanaka Y, Uchino H, Shimizu T, Yoshii H, Niwa M, Ohmura C, Mitsuhashi N, Onuma T and Kawamori R: Effect of metformin on advanced glycation endproduct formation and peripheral nerve function in streptozotocin-induced diabetic rats. Eur J Pharmacol 376: 17-22, 1999.

34. Gudbjornsdottir S, Friberg P, Elam M, Attvall S, Lönnroth P and Wallin BG: The effect of metformin and insulin on sympathetic nerve activity, norepinephrine spillover and blood pressure in obese, insulin resistant, normoglycemic, hypertensive men. Blood Press 3: 394-403, 1994.

35. Nicol GD: Nerve growth factor, sphingomyelins, and sensitization in sensory neurons. Sheng Li Xue Bao 60: 603-604, 2008.

36. Wang S and Zhou Y: Baicalein inhibits neuroapoptosis via pathways in sevoflurane induced rats. Transl Neurosci 9: 88-98, 2018.

37. Osinde M, Mullershausen F and Dev KK: Phosphorylated FTY720 stimulates ERK phosphorylation in astrocytes via S1P receptors. Neuropharmacology 52: 1210-1218, 2007.

38. Liu J, Zhang X, Zhang W, Gu G and Wang P: Effects of sevoflurane on young male adult C57BL/6 mice spatial cognition. PLoS One 10: e134217, 2015. 